\title{
IAS 21-THE EFFECTS OF CHANGES IN FOREIGN EXCHANGE RATES: AN EXAMPLE OF PEGASUS
}

\author{
DOI: 10.17261/Pressacademia.2018.930 \\ PAP- V.7-2018(83)-p.437-441
}

\section{E. Asena Deniz}

Işık University, Büyükdere Cad. Maslak Kampüsü 34398, Istanbul, Turkey.

elvanasena.deniz@isikun.edu.tr

\section{To cite this document}

Deniz, E. A. (2018). IAS 21-The effects of changes in foreign exchange rates-an example of Pegasus. PressAcademia Procedia (PAP), V.7, p.437441.

Permemant link to this document: http://doi.org/10.17261/Pressacademia.2018.930

Copyright: Published by PressAcademia and limited licenced re-use rights only.

\section{ABSTRACT}

Purpose - In recent years, one example of situations emerging as a result of globalization which cause changes in accounting is exchange rate. The aım that is absorbing IAS21 and anlaysing Pegasus airline.

Methodology - Interaction between countries, namely trading, bears that each country has its own currency and those countries prepare their financial statements in their own currency as well as they guide to change of exchange rates arising on financial state ments prepared by companies traded on international market. There are necessary explanations on how to deal with these changes under the heading of IAS 21 exchange rate effects.

Findings- This study briefly focuses on the purpose and scope of the standard to which IAS 21 refers, the concept of the valid currency in the Standard, the net investment in foreign operations and the disclosure of monetary and non-monetary items.

Conclusion- it is explained how the changes occuring in the exchange rate will be accounted for and how this accounting will be reflected in the financial statements. For this purpose, how the effects of exchange rate changes on the financial statements of the airline company, Pegasus, which is open to public, have been examined.

Keywords: IAS 21, exchange rate, recognition, financial statements.

JEL Codes: F31, O24, Z00

\section{TMS 21 - KUR DEĞişiKLiĞiNIN ETKISI: PEGASUS ÖRNEĞi}

\section{ÖZET}

Amaç - Son zamanlarda, globalleşme sonucu ortaya çıkan ve muhasebesel olarak değişiklik ve farklılık meydana getiren durumlardan bir taneside kur değişimleridir. Kur değişimlerine açıklık getirmek amacıyla hazırlanan standardı özümsemek ve bu standard doğrultusunda halka açık olan bir şirket incelenmiştir.

Yöntem -Ülkeler arasında ki etkileşim yani ticaret sonucunda, her ülkenin kendine ait bir para birminin olması ve o ülkelerin kendi para birimiyle finansal tablolar hazırlaması ve ayrıca uluslarası piyasalarda işlem gören firmaların hazırladıkları Finansal tablolarda ortaya çıkan kur değişimlerinin yansıtılmasına yönelik yol göstermek amacıyla TMS 21 kur değişimin etkilieri başlığı altında bu değişikliklerle nasıl başa çıkılabileceği konusunda gerekli açıklamalar yer almaktadır.

Bulgular- Bu çalışma kısaca Tms 21 in değinmiş olduğu standardın amacını ve kapsamını, Standartta yer alan geçerli para birimi kavramı,yurt dışındaki işletmeye yapılan net yatırım ve parasal ve parasal olmayan kalemlerin açıklanması üzerinde durulmuştur.

Sonuç- Kur değişiminde meydana gelen değişimlerin nasıl ve neye göre muhasebeleştirileceği bu muhasebeleştirilmenin finansal durum tablolarına nasıl yansıtılacağı açıklanmıştır. Bu amaç dogrultusunda da halka açık ve bir havayolu şirketi olan Pegasusun mali tablolarına kur değişim etkilerinin nasıl yasıtıldıgının incelenemsidir.

Anahtar Kelimeler: TMS 21, döviz kuru, finansal tablolar.

JEL Kodları: F31, O24, Z00 


\section{GiRiş}

Ülkelerin muhasebe sistemleri her ülke için farklılık içermektedir. Bu farklııkların ülkelerin bulunduğu coğrafya, yaşayış tarzı, ülkenin sahip olduğu kültür vb. birçok sebebi vardır. Son yıllarda uluslararası şirketlerinde artması ile muhasebe uygulamalarında ülkeler arasındaki farklııklar, finansal verilerin karşılaştırılmasını zorlaştırmakta, sermaye piyasalarının gelişmesini engellemekte ve uluslararası şirketlerin faaliyetlerini de zorlaştırmaktadır. Bu nedenlerden dolayı hem tüm muhasebe standartlarını bir formatta oluşturmak hem de kısıtlamaların önüne geçebilmek için Uluslarası Muhasebe Satandartları olan UFRS/TFRS ve UMS/TMS üretilmiştir.

Uluslarası ticaret sonucunda, ülkeler arasında para biriminden kaynaklı birçok sorunlar ortaya çıkmıştır. Bu sebeple de, muhasebe kayıtlarının geçerli para biriminden tutulması ve raporlanması, farklı para birimleri ile ticaret yapan firmaların elde ettikleri döviz gelirlerinin dae ulusal para birimine çevrilmesini zorunlu hale gelmiştir. Tüm bu işlemlerin yapılabilmesi için geliştirilen Uluslararası Finansal Raporlama Standartlarına (UFRS)'ye uyumlu çıkarılan Türk Muhasebe Standartları, bu konuyu TMS 21 Kur Değişiminin Etkileri standardında yer almaktadır

\section{STANDARDIN AMACI VE KAPSAMI}

\section{a. Standardın Amacı}

TMS 21 Standardına göre; bir işletme; yabancı para birimlerinde işlemler yapmak ya da yurtdışında işletmeye sahip olmak suretiyle yabancı faaliyetlerde bulunabilir. Ayrıca, bir ișletme finansal tablolarını bir yabancı para biriminde sunabilir. Bu Standardın amacı, yabancı para işlemlerin ve yurtdışındaki işletmelerin finansal tablolara nasıl dahil edileceğini ve finansal tablolarda kullanılan para birimine nasıl çevrileceğini düzenlemektir.(TMS21 - Ek P-1)

Muhasebenin temel kavramlarından olan parayla ölçülme kavramından dolayı muhasebe işlemleri ulusal para birimlerine göre yapılmalıdır. Bu sebepten dolayı, bu standardın basit ifadeyle amacı; yabancı para işlemlerin ve yurtdışındaki işletmelerin finansal tablolara nasıl dahil edileceğini ve finansal tablolarda kullanılan para birimine nasıl çevrileceğini düzenlemektir. Kısaca yabancı para biriminin, ulusal para bi rimine nasıl dönüştürülmesi gerektiğini açıklar.

Bir diğer amacı da, Hangi döviz kuru/kurlarının kullanılacağı ve döviz kurlarındaki değişimin finansal tablolar üzerindeki etkilerinin nasıl raporlanacağı bu standardın temelini oluşturmaktadır.( TMS21 - Ek P-2)

\section{b. Standardın Kapsamı}

Standardın uygulandığı ve uygulanmayacağı alanlar bulunmaktadır. TMS 39 birçok yabancı para türev araçlarına uygulandığından dolayı türev araçları bu standartın kapramında değildir. Ancak yabancı para türev araçlarında ve bir işletmenin türev araçlarına ilişkin tutarları geçerli para biriminden finansal tablolarda kullanılan para birimine çevirirken, bir işletmenin finansal tablolarının bir yabancı para biriminde sunulmasında uygulanır.

Yurtdışındaki işletmedeki net yatııım da dahil olmak üzere, yabancı para kalemler için yapılan finansal riskten korunma muhas ebesinde ve yabancı para işlemlerden kaynaklanan nakit akışlarının Nakit Akış Tablosundaki sunumunda ya da yurtdışındaki işletmenin nakit akışlarının çevriminde uygulanmaz.

\section{TMS 21 deki Belirli Kavramların Açıklaması}

\section{a. Geçerli Para Birimi Kavramı}

Geçerli para birimi kavramı, TMS-21 Md.8 de şöyle tanımlanmaktadır. "Işletmenin faaliyet gösterdiği temel ekonomik çevrenin para birimidir". Geçerli para birimi kullanımı bakımından iki türlü ele alınmaktadır. Birincisi işletme bireysel olarak yabancı paralı işlemlerde bulunabilir. Ikincisi yurt dışında faaliyette bulunan işletmeler olabilir. Her iki durumda da geçerli para biriminin tespit edilmesi ve yabancı paralı işlemlerin ve yabancı para biriminden düzenlenen finansal tabloların geçerli para birimine çevrilmesi gerekir (Özerhan ve Yanık, 2012).

Göstergelerin karışık ve geçerli para biriminin açık olmadığı durumlarda şirket yönetimi; ekonomik koşullarında göze alarak kendi bel irleyeceği para birimini kullanır. TMS-21 Kur Değişiminin Etkileri standardına göre; Bir işletmenin geçerli para birimi, bir kere belirlendikten sonra, işletmeyi etkileyen temel işlemler, olaylar ve koşullar değişmediği sürece geçerli para birimi değişmez. Para biriminde bir değişiklik olduğu durumlarda ise değişimden itibaren ileriye dönük olarak muhasebeleştirilir. İşletme tüm kalemleri yeni geçerli para birimine değişim tarihindeki döviz kurunu kullanarak çevirir.

\section{b. Yurtdışındaki İşletmeye Yapılan Net Yatırım}

Net yatırım; Yurtdışındaki işletmenin net aktiflerinde raporlanan payıdır. TMS 21 EK-15 e göre; bir işletme yurt dışı yatırım amaçlı girişimlerde bulunabilir. Bu girişimlerin ekonomik etkileri muhasebede ele alınır. İşletmelerin öngörülebilir bir gelecekte gerçekleşmesi planlanmayan ya da beklenmeyen bir kalem, özünde işletmenin yurtdışındaki işletmedeki net yatırımının bir parçasıdır ve bu Standardın 32 nci ve 33 üncü paragraflarına göre muhasebeleştirilir. Parasal bir kalemden kaynaklanan kur farkları, raporlayan işletmenin bireysel finansal tablolarında ve yurtdışındaki işletmenin kendi finansal tablolarında kar ya da zarar olarak muhasebeleştirilir.

\section{c. Parasal Kalemler}

Elde tutulan para ile sabit veya belirlenebilir bir tutarda para olarak alınacak veya ödenecek varlık ve borçlardır. Parasal bir kalemin temel niteliği, sabit ya da belirlenebilir tutarda paranın ödenmesi yükümlülüğüdür. Örnekle ifade etmek gerekirse; nakit ödenecek emeklilik tazminatları ve çalışanlara sağlanan diğer haklar vb. 
Parasal olmayan bir kalemin temel niteliği ise sabit ya da belirlenebilir tutarda para biriminin alınması hakkının olmaması durumunu ifade eder. Şerefiye; maddi olmayan duran varlıklar; stoklar bu duruma örnek verilebilir.

\section{YABANCI PARA BIRIMLERININ MUHASEBELEŞTiRILMESI VE RAPORLANMASi}

\section{a. ilk muhasebeleştirme}

İşletmenin, fiyatları yabancı bir para biriminde belirlenen mal ve hizmetleri alıp satması; işletmenin, borç ya da alacak tutarları yabancı bir para biriminde belirlenen kredi alması ya da borç vermesi veya işletmenin, yabancı bir para birimi cinsinden varlık elde etmesi ya da elden çıkarması ile bu tür yükümlülüklerin oluşması veya yerine getirilmesi durumlarını kapsar. Bir yabancı para ilk muhasebeleştirme sırasında; yabancı para birimindeki tutara, geçerli para birimi ile işlem tarihindeki yabancı para birimi arasındaki geçerli kur uygulanarak, geçerli para biriminden kaydedilir.

\section{b. İzleyen raporlama dönemi sonlarında raporlama}

Standarda göre her raporlama dönemi sonunda; Yabancı para parasal kalemler kapanış kurundan çevrilir, Tarihi maliyet cinsinden ölçülen yabancı para birimindeki parasal olmayan kalemler işlem tarihindeki döviz kuru kullanılarak çevrilir ve gerçeğe uygun değerden ölçülen yabancı para birimindeki parasal olmayan kalemler gerçeğe uygun değerin belirlendiği tarihteki döviz kurları kullanılarak çevrilir. Bir kalemin defter değeri, ilgili diğer Standartlar ile birlikte belirlenir. Bazı kalemlerin defter değeri iki ya da daha fazla tutar karşılaştırılarak belirlenir. Örneğin, stokların defter değeri "TMS 2 Stoklar" Standardına göre maliyet ya da net gerçekleşebilir değerden düşük olanıdır.

\section{c. Kur farklarının muhasebeleştirilmesi}

Uluslarası çevrim işlemlerinin gerçekleştirilmesi durumunda işlem tarihi ile ödeme tarihi arasında döviz kurunda meydana gele n değişim sonucunda kur farkları oluşur. Parasal olan işlem, gerçekleştiği muhasebe döneminde kapanıyorsa, tüm kur farkı aynı dönemde finansal tablolara yansıtılır. Ancak, işlem bir sonraki muhasebe döneminde kapanıyorsa, kapanma tarihine kadar her bir dönemde muhasebeleştirilecek kur farkları her dönemde döviz kurlarında meydana gelen değişime göre belirlenir ve tahakkuk ettirilir.

Parasal olmayan işlemlerde meydana gelen kur farklılıklarında ise oluşan kazanç ya da zarar diğer kapsamlı gelirde muhasebeleştirilirse, bu kazanç ya da zararın kurdan kaynaklanan kısmı da diğer kapsamlı gelirde muhasebeleştirilir. Ancak, kazanç ya da zarar, gelir tablosunda muhasebeleştirilirse, bu kazanç ya da zararın kurdan kaynaklanan kısmı da gelir tablosunda muhasebeleştirilir.

\section{SUNUM PARA BIRIMI}

Standartta ifade edilen para birimi işletmelerin finansal tablolarda sunduğu para birimidir. Finansal tablolarda sunulan para birimleri işletmelerinin kullandıkları para biriminden farklı olabilir. Finansal tablolarda kullanılan para biriminin işletmenin geçerli para biriminden farklı olması durumunda işletme, faaliyet sonuçlarını ve finansal durumunu finansal tablolarda kullanılan para birimine çevirir. İthalat yapan ve ya yabancı piyasalara açılmış işletmeler, tablolarının hem o ülkenin kendi para pirimi hemde kendi para birime göre hazırlarlar. Döviz kurlarının önemli ölçüde dalgalanma olmaması şartıyla, uygulama kolaylığı sağlamak için, gelir ve gider kalemleri için işlemlerin yapıldığı tarihlerdeki döviz kurlarına yaklaşık bir kurun, örneğin dönemin ortalama kurunun kullanılmasına izin verilmektedir. Ancak, döviz kurlarının önemli ölçüde dalgalanması durumunda dönem için ortalama kur kullanılmaz.

\section{KUR FARKLARININ FINANSAL TABLOLARA YANSIMASI. PEGASUS}

Grup, başlıca ABD Doları ve TL cinsinden kur riskine maruz kalmaktadır.

Aşağıdaki tablo Grup'un ABD Doları ve TL kurlarındaki \%10’luk artışa ve azalışa olan duyarlılığını göstermektedir. \%10’luk oran, üst düzey yöneticilere Grup içinde kur riskinin raporlanması sırasında kullanılan oran olup, söz konusu oran yönetimin döviz kurlarında beklediği olası değişikliği ifade etmektedir. Duyarlılık analizi sadece dönem sonundaki açık yabancı para cinsinden kalemleri kapsar ve söz k onusu kalemlerin yıl sonundaki \%10’luk kur değişiminin etkilerini gösterir.

\begin{tabular}{|l|c|c|}
\hline 31 Aralık 2017 & Doları & TL \\
\hline 1. Ticari Alacak & 20.358 .928 & 74.550 .319 \\
\hline 2a. Parasal Finansal Varlıklar & 452.531 .681 & 49.136 .540 \\
\hline 2b. Parasal Olmayan Finansal Varlıklar & - & - \\
\hline 3. Diğer & 146.780 .474 & 10.882 .284 \\
\hline 4. DÖNEN VARLIKLAR & 619.671 .083 & 134.569 .143 \\
\hline 5. Ticari Alacaklar & - & - \\
\hline 6a. Parasal Finansal Varlıklar & - & - \\
\hline 6b. Parasal OImayan Finansal Varlıklar & - & - \\
\hline 7. Diğer & 69.286 .432 & 667.356 \\
\hline 8. DURAN VARLIKLAR & 69.286 .432 & 667.356 \\
\hline 9. TOPLAM VARLIKLAR & 688.957 .515 & 135.236 .499 \\
\hline
\end{tabular}




\begin{tabular}{|l|r|c|}
\hline 10. Ticari Borçlar & 39.864 .039 & 70.606 .121 \\
\hline 11. Finansal Yükümlülükler & 175.699 .621 & - \\
\hline 12a. Parasal Olan Diğer Yükümlülükler & 5.055 .674 & 87.401 .848 \\
\hline 12b. Parasal Olmayan Diğer Yükümlülükler & - & - \\
\hline 13. KISA VADELi YÜKÜMLÜLÜKLER & 220.619 .334 & 158.007 .969 \\
\hline 14. Ticari Borçlar & - & - \\
\hline 15. Finansal Yükümlülükler & 316.325 .435 & - \\
\hline 16a. Parasal Olan Diğer Yükümlülükler & - & - \\
\hline 16b. Parasal Olmayan Diğer Yükümlülükler & - & - \\
\hline 17. UZUN VADELi YÜKÜMLÜLÜKLER & 316.325 .435 & - \\
\hline 18. TOPLAM YÜKÜMLÜLÜKLER & 536.944 .769 & 158.007 .969 \\
\hline
\end{tabular}

\section{SONUÇ}

\section{KAYNAKLAR}

Özerhan, Y., Yanık, S. (2012). IFRS/IAS ile uyumlu TMS/TFRS açıklamalı ve örnek uygulamalı Türkiye Muhasebe Standartları Türkiye Finansal Raporlama Standartları. Türmob Yayınları, 337, 2.Baskı.

Yılmaz, F. TMS 21 kur değişiminin etkileri. ìsmmo yayınları,99/4 .bölüm.

http://iibfdergi.bartin.edu.tr/wp-content/uploads/2017/01/21-TMS-21-\%E2\%80\%9CKur-De\%C4\%9Fi\%C5\%9Fiminin-EtkileriStandard\%C4\%B1\%E2\%80\%9Dn\%C4\%B1n-Uygulanmas\%C4\%B1-ve-Finansal-Tablolara-Yans\%C4\%B1mas\%C4\%B1.pdf

http://archive.ismmmo.org.tr/docs/yayinlar/kitaplar/99/4.bolum.pdf

http://dergipark.gov.tr/download/article-file/309519

http://iibfdergisi.ksu.edu.tr/download/article-file/107686

http://www.gureli.com.tr/vk/makaleler//tms-21-kur-degisiminin-etkileri-standardi-kapsaminda-finansal-tablolarin-cevrimi

http://www.kgk.gov.tr/Portalv2Uploads/files/DynamicContentFiles/T\%C3\%BCrkiye\%20Muhasebe\%20Standartlar\%C4\%B1/TMSTFRS2011Se ti/TMS21.pdf

http://www.kgkuzder.org.tr/upload/files/1_Ahmet_Gursoy_122016.pdf

http://www.pegasusyatirimciiliskileri.com/tr/operasyonel-ve-finansal-veriler/finansal-tablolar-denetci-raporlari 
